\section{GPIAG News}

\section{GPIAG Annual General Meeting 22 June 2007}

The seventh Annual General Meeting of the General Practice Airways Group ("the Company") will be held at Keele University on 22nd June 2007 at 13:00 hours. We would welcome your attendance.

The business of the meeting will be:

1. To review the achievements of the Company in 2006 and its business priorities for 2007/8.

2. To receive the Company's accounts and reports of the directors and accountants for the period 1st January 2006 to 31 December 2006;

3. To acknowledge the retirement of Professor Sean Hilton who retires as trustee of the General Practice Airways Group at the end of June 2007.

4. To consider and, if thought fit, to pass the following ordinary resolutions:

a. That Dr Patrick White, having indicated his willingness to act, be appointed as trustee of the Company from 23 June 2007;

b. To re-appoint Bentley Jennison as auditors to the charity until the completion of the next Annual General Meeting of the Company at which accounts are laid and to authorise the trustees to fix their remuneration.

\section{GPIAG Website: http://www.gpiag.org}

Following a major upgrade of our website we were delighted to include new sections for our members on GPIAG policy activities and to introduce a new section especially for our nurse members. We hope that you like the revised website and that you find it more user-friendly and easier to navigate. In the near future, we aim to provide an online survey facility wherein you can submit your views on the website and offer ideas for improvements and enhancements.

If you require any assistance with your log-in information please contact us at info@gpiag.org

\section{GPIAG - Nurses and Allied Health Professionals}

The GPIAG is continuing to make progress on the new range of materials being developed specifically to support the needs of nurses working in primary care respiratory medicine. Our document on skill levels for delivering high quality respiratory care by nurses in primary care, and the first three protocols (Spirometry Protocol for COPD, Protocol for Management of Acute Exacerbations of COPD, and Protocol for COPD Assessment and Review in Primary (are) will be launched soon and available for download from our website.

Further protocols and a series of practice group directives (PGDs) on key issues will also be launched later this summer.

\section{GPIAG Opinion Sheets}

In addition to the Primary Care Respiratory Journal, the GPIAG produces a range of educational materials for members which includes a series of opinion sheets. These are concise, easy-tofollow documents on common respiratory topics aimed at providing practical guidance for those working in primary care respiratory medicine. Currently, we have eleven opinion sheets on a range of topics, and new opinion sheets are being added all the time. A recent report from GP Magazine (13 April 2007) highlighted the opinion sheets as being "...packed with relevant information... What we need is the nitty-gritty, and it is all packed in here." See what you think by logging on to our website http://www.gpiag.org and go to the publications section.

Opinion sheets are available free of charge to members of the GPIAG and can be downloaded from our website - see http://www.gpiag.org. For non-members, full details of the benefits of membership are available at http://www.gpiag. org/about/join.php.

\section{Become more involved with the GPIAG}

If you are interested in becoming more involved with the GPIAG please contact us for an informal discussion as to how you can help. You may be interested in standing for election to one of our committees - the research committee, education committee, practice nurse working group, or general committee - or alternatively you might be interested in joining our policy network to help shape the documents and submissions that we prepare when making representation to bodies such as NICE, the Department of Health and the Healthcare Commission. For more information about how you can be more involved please contact us at info@gpiag.org. 


\section{British Lung Foundation News}

\section{Lung disease sufferers - their lack of treatment and care}

People with lung disease are 'blowing the whistle' on the lack of treatment and care available to them. One person in seven in the UK is affected by lung disease. Lung disease is the country's second biggest killer, with 117,456 deaths in 2004.

With UK death rates almost double the European average, the British Lung Foundation is launching an Action Plan for Lung Health during its Breathe Easy Week, 11-18 June 2007. The Action Plan is based on what sufferers themselves say should be done to combat escalating rates of lung disease and the charity hopes that health professionals will also support its aims.

Almost two-thirds (62\%) of those surveyed by the charity said respiratory disease should be a priority for local healthcare services. Nearly half (43\%) want an end to the current postcode lottery of treatment and care, while 35\% highlight the lack of respiratory specialists in the NHS, including radiologists, nurses and physiotherapists. Around a quarter of those surveyed want more research into lung disease prevention (27\%), access to better community services to reduce emergency hospital admissions (25\%), and easily accessible pulmonary rehabilitation and exercise classes (25\%). Around a fifth (21\%) want high quality information and support to maximise independence and better screening and diagnosis by GPs and health professionals (19\%).

The charity also asked people with lung disease what they most wished for themselves. More than half wished they didn't have to live in fear of an attack of breathlessness and nearly a third said they would love to be able to play with their children or grandchildren. Others wanted to be able to run, dance and make love.

Over three thousand members of the British Lung Foundation's Breathe Easy support groups took part in the survey as part of the charity's Blow the Whistle on Lung Disease campaign.

For further information contact Jill Morrell, Head of Public Affairs, British Lung Foundation. Tel: 0207688 5565. e-mail: jill.morrell@blf-uk.org

\section{Asthma UK News}

\section{Asthma UK launches new Emergency Care Asthma Pack}

To mark World Asthma Day on 1 May 2007, Asthma UK highlighted the need for improved asthma care to reduce emergency hospital admissions and launched an Emergency Asthma Care Pack for healthcare professionals; this is a new resource that will assist healthcare professionals who work in settings where they are likely to encounter people having an asthma attack

The pack shows the process of care from when a person with asthma first presents, to their follow-up arrangements and discharge. It contains guidance on evidence-based standards of emergency asthma care, no matter where a person with asthma is being treated, templates to adapt to individual settings (e.g. an assessment form, discharge letter, Patient Group Directives), and an audit tool plus training slides and patient information booklets.

The Emergency Asthma Care Pack was sent to around 25,000 key healthcare professionals across the UK in primary and secondary care in early May 2007, including GP practices, A\&E departments and respiratory professionals, as well as Directors of Public Health and Chief Executives of Acute, Ambulance and Primary Care Trusts.

It is available in both paper and CD-rom format, is downloadable from the Asthma UK website www.asthma. org.uk, and is available from the Asthma UK Supporter and Information Team on +44 (0)20 77865000 or by e-mailing info@asthma.org.uk.

\section{IPCRG News}

\section{External affairs}

The IPCRG is delighted to report that Wonca is due to confirm our status as an Organisation in Collaborative Relations at their Executive meeting in June. Jim Reid will represent the IPCRG as an observer.

The final version of the Brussels Declaration on Asthma, to which we made a significant contribution, is close to launch. The revised European Pharmacovigilance Strategy to which we contributed with EFA is now published at http://ec.europa.eu/ enterprise/pharmaceuticals/pharmacovigilance_acs/index.htm

\section{Education}

We are delighted to have received an educational grant from Pfizer Europe to write and publish evidence-based international smoking cessation guidelines for primary care practitioners. An expert panel - including members from Norway and Australia, where national guidelines already exist - met in London on 3rd May to discuss and draft guidelines for international review and publication on our website www.theipcrg.org. We will also produce PowerPoint slides and hope that there will be a future opportunity to translate the guidelines. We will also be producing for download a 2page smoking cessation desktop helper. 


\section{Membership}

PCRG Sri Lanka has made fantastic progress. Established less than a year ago, it led the pre-congress symposium on Asthma and COPD at the annual academic sessions of the College of General Practitioners, which was an unqualified success. The group has now started a national study of the prevalence of respiratory diseases in primary care. Meanwhile Osman Yusuf has been busy recruiting colleagues on a lecture tour including Rawalpindi and Lahore, and has appeared on national television to raise awareness about asthma and allergy. In April, Thys van der Molen ran a COPD workshop and discussed developing a national group at the National Primary Care conference in Antalya, Turkey organised by Hakan Yaman. Hilary Pinnock, Bart Thoonen and Monica Fletcher attended the AIMEF CardioPneumo conference organised by Antonio Infantino in Bari in May postponed from January. David Price has made new contacts with Slovenian GPs. An IPCRG speaker will attend the European Wonca meeting in Paris in October to present the "clinical year review" for asthma and COPD.

\section{Research}

Two of our sub-groups from the Oslo 2006 meeting have made progress. Alan Crockett chaired a group in London in March to produce a state of the art review on spirometry in primary care. The HEALTH study, an exercise intervention in people with mild to moderate COPD led by Adrian Taylor and set up by Rupert Jones, is about to recruit patients thanks to support from the IPCRG.

Contact Details:

Sam Louw, sam.knowles@abdn.ac.uk

+44 (0)1224552427

www.theipcrg.org

\section{Education for Health News}

\section{Essentials of Primary Care Nursing - the perfect introduction to managing long term conditions in primary care}

General practice is often the first port of call for people with a health problem. As well as the presentations for acute illness, the problem could be anything from poorly controlled asthma to people needing education about diabetes, wanting advice following a heart attack, and patients needing help with managing the lifestyle implications of chronic heart failure. All of these issues can and will be dealt with by the general practice team; this makes general practice one of the most rewarding and exciting places to work, and the role of the practice nurse in managing long term conditions is invaluable.

Our new 5-day course provides an introduction to general practice for nurses who will be involved in managing long term conditions and meeting the requirements of the new General Medical Services contract through the Quality Outcomes Framework (QOF).

Further information is available from: e.mccutecheon @educationforhealth.org.uk

\section{Open University Revalidation success}

We have had a truly outstanding result in our recent Open University revalidation event. Our BSc and Diploma of Higher Education in Respiratory Care were both revalidated for five years with no conditions whatsoever. It is particularly appropriate that this has coincided with registering our 100th student on the BSc programme.

The panel was very impressed with our work and particularly commended us for our innovative and forwardlooking programme team, excellent student support structures and student handbook, the induction and support offered to trainers, and the quality of our learning materials. We are very proud to be able to demonstrate how we teach and support our students in a way that enables them to make a real difference in their clinical practice.

The BSC and the Diploma are flexible programmes for health professionals working in the respiratory field. The modular distance-learning approach allows busy professionals to combine study with practice. Study days are provided at Warwick, regional centres such as Stirling, Manchester and London, and at any local venue on a satellite basis where they are commissioned. The Diploma programme has no compulsory modules and there is a choice of 10 option modules at HE Level 2 (diploma level). The Degree programme has two compulsory core modules (Evidence-Based Healthcare and the Project) and a choice of 8 option modules at HE Level 3 (degree level) as well as the diploma level options where appropriate.

Recruitment is now taking place for the next intakes. For further details contact a.eagles@educationforhealth.org.uk

\section{National Clean Air Award Scheme}

We have achieved a Gold Award from The National Clean Air Award Scheme in recognition of our outstanding commitment in providing a tobacco smoke-free environment to protect the health, safety and wellbeing of all who enter our premises.

The National Clean Air Award is a Roy Castle Lung Cancer Foundation initiative and is endorsed by the Chartered Institute of Environmental Health, Asthma UK and the British Lung Foundation.

As part of this award, Education for Health achieved the following:

- The company premises and grounds are completely smoke-free 
- We actively discourage smoking at the entrances and exits to our premises

- We offer appropriate stop smoking advice and support to employees who smoke and wish to quit

- We have a separate written no-smoking policy.

\section{Ban on smoking in public places}

With the imminent introduction in July of the ban on smoking in public places in England which aims to protect the general public from the harmful effects of passive smoking, patients are being more proactive in asking for help to quit. Scotland was the first part of the UK to enforce a ban through law, and figures issued in March 2007 showed that 46,000 people across Scotland tried to quit smoking last year by contacting cessation services, while 70 per cent of the population support the new law and almost 80 per cent consider it a success.
Health professionals will continue to play a key part in encouraging and supporting people to stop smoking. Understanding the stages that people must go through to achieve a successful quit attempt is fundamental to supporting patients through the cessation process.

To assist health professionals to become effective agents for change and to enhance their skills in encouraging and supporting patients through the quitting process, Education for Health has updated its Smoking Cessation module. This is complemented by our new interactive one-day short course called 'Partners in Care'. This focuses on patient-centred care and shared decision-making. It will provide new ideas and reenergise those healthcare professionals who have been working in this area for many years.

Further information is available from k.whitehead @educationforhealth.org.uk

Available online at http://www.thepcrj.org 